\title{
Mapping Habitats in Alpine Regions Using Multi-Temporal RapidEye Data
}

\author{
Anastasia POLYCHRONAKI, Nadine SPINDLER, Alexander SCHMIDT, \\ Barbara STOINSCHEK, Marc ZEBISCH, Kathrin RENNER, \\ Claudia NOTARNICOLA and Ruth SONNENSCHEIN \\ EURAC Research, Bolzano/Italy · anastasia.polychronaki@eurac.edu
}

This contribution was double-blind reviewed as extended abstract.

\begin{abstract}
This work aimed to investigate the potential of remote sensing to provide information on the spatial distribution of habitats in the Alpine region. Specifically, the performances of different classification methods, namely Maximum Likelihood (ML), Decision Tree (DT) and Support Vector Machine (SVM) were investigated for land-cover mapping using multitemporal RapidEye data. Results showed that SVM (85\% overall accuracy) outperformed ML (80\% overall accuracy) and DT (79\% overall accuracy). The resulted land-cover classes were subsequently reclassified into habitat classes using a spatial kernel approach. Findings suggest that the inclusion of solar radiation layers in the classification procedure as well as the use of multi-temporal images improves the classification accuracy by $4 \%$ and $10 \%$, respectively.
\end{abstract}

\section{Introduction}

Remote sensing has shown to be a valuable tool for mapping habitats, but as yet, the potential of remote sensing has not been fully investigated for mapping habitats in Alpine regions. Using satellite imagery to map these habitats is accompanied by two major challenges: topography and the complexity of the Natura 2000 habitat types. The first causes different reflectances of the same features on the surface due to different illumination intensities. The latter refers to that, in contrast to land-cover mapping, Natura 2000 habitats cannot be regarded as homogeneous patches of a single or few dominant species (THOONEN et al. 2013), but rather complex mosaics or transitions of vegetation types (VARELA et al. 2008). Therefore, the complex nature of Natura 2000 habitats could hamper the direct mapping of habitats when using satellite imagery.

The aim of this work was to develop a method for identifying natural and semi-natural habitats in alpine regions using EO data. The specific objectives were: 1) to investigate the performance of different classification algorithms for mapping alpine habitats, 2) to investigate whether the inclusion of solar radiation layers can improve the classification accuracy as a solution to compensate for the radiometric distortions caused by the topography, and 3) to investigate whether the use of multi-temporal images can improve the classification accuracy of complex habitats types. 


\section{Study Area and Dataset Description}

The study area of Rieserferner-Ahrn Nature Park, which is part of the Natura 2000 network, was selected for this investigation and is The Park, located in the Northeast of South Tyrol, covers an area of $313 \mathrm{~km}^{2}$. The available EO data for this work included multi-temporal RapidEye Level 1B data (6.5 m spatial resolution) acquired at four different dates (22-072009, 29-07-2009, 03-10-2009, 31-07-2010). Auxiliary data included RGB orthophotos and a Digital Elevation Model (DEM) $(2.5 \mathrm{~m})$. Four solar radiation layers, one for each RapidEye image, were generated from the available DEM. In addition, a very detailed thematic map of vegetation classes produced from field work by experts was available for the test site Prettau. The test site is located on the northern part of the Nature Park and covers $13 \mathrm{~km}^{2}$.

\section{Methods}

The first step of the methodology involved pre-processing of the images. All images were orthorectified using Toutin's model, (TOUTIN 2003; OrthoEngine v10.2 software) and Ground Control Points (GCPs) that were manually selected from the orthophotos. The radiance values of the RapidEye images were then transformed in Top-of-Atmosphere reflectance values (RapidEye FAQ, 2010). Next, a mask was created to exclude clouds and shadowed areas from the classification procedure.

Taking into account the heterogeneous nature of the Natura 2000 habitats, a two-level procedure was chosen to derive the final product: at level one (lower level) the multitemporal RapidEye data were classified into land-cover classes which were subsequently reclassified at level two (higher level) into habitat classes. Prior to this procedure, the classification scheme had to be defined. For defining the land-cover classes that could be extracted from the multi-temporal RapidEye images, the unsupervised Iterative SelfOrganising Data Analysis Technique (ISODATA) algorithm was performed resulting in 100 unlabelled clusters. The clusters were evaluated using the thematic map of the vegetation classes and labels were assigned to each cluster. During this procedure, some clusters were combined and classes of the thematic map were aggregated to provide for appropriate labelling. The final classification scheme included twelve land-cover classes: water bodies, shrubs, mountain pines, natural grasslands, semi-natural grasslands, nutrient rich grasslands, wetlands, scree, pioneer vegetation, rocky slopes, forest and alder trees. The land-cover classes were subsequently translated into habitat classes to arrive at the second classification level which was defined based on experts' knowledge and on different characteristics of each habitat, such as altitude and minimum area of coverage (LASEN \& WiLHALM 2004; ElLMAUER 2005). Following the definition of the classification scheme, samples were collected for training and validation purposes for each land-cover class. A grid was created from the RapidEye images, which was overlaid on the orthophotos. Samples were collected randomly from a $2 \times 2$ pixels window by photointerpretation of the orthophotos. In total, 8000 samples were used for the twelve classes.

Since classification is a key step in the proposed methodology and given the lack of related studies in Alpine regions, different classification algorithms were investigated to map landcover classes accurately: the traditional Maximum Likelihood (ML), and more advanced 
algorithms such as decision tree (DT) and Support Vector Machine (SVM). All five RapidEye bands were used together with the four solar radiation layers during the classification of the land-cover classes. In a subsequent step, the best performing of the aforementioned classification algorithms was employed to investigate to what degree the classification accuracy improves with 1) the inclusion of the solar radiation layers to compensate for the radiometric distortions caused by the topography and 2) the use of multitemporal imagery to overcome difficulties in classifying habitats of the Alpine region.

The final step of the methodology was the reclassification of the land-cover classes to habitat classes (SCHMIDT 2012) which was carried out using the Spatial Reclassification Kernel (SPARK) approach of THOONEN et al. (2010). This procedure is based on a moving window (kernel) approach which centres one pixel at a time and then analyses its surrounding composition of land-cover classes. According to this composition the habitat is defined. In this work, the percentage cover of each land-cover class (from 40 to $100 \%$ ) was used to assign the habitat. For example, if $55 \%$ of the surrounding land-cover class is matched with habitat $\mathrm{A}$ and $35 \%$ with habitat $\mathrm{B}$ then the centre pixel is assigned to habitat A. Furthermore, each habitat was defined in terms of elevation range, by including in the reclassification procedure the DEM, and in terms of minimum area of coverage. The area of each of the created habitats was calculated and if the habitat patches were not consistent with the specifications they were merged with neighbouring habitats.

\section{Results}

Results indicated that SVM (85\% overall accuracy) outperformed ML ( $80 \%$ overall accuracy) and DT (79\% overall accuracy). The best performing approach, i.e. SVM, was subsequently employed to investigate the influence of integrating solar radiation as an additional information layer into the classification process. A significant $(p<0.05)$ increase of the overall accuracy was achieved when the solar radiation was added $(85 \%)$ in the classification procedure compared to only using the multi-temporal RapidEye data $(81 \%)$. In particular, the autumn acquisition proved to be valuable information to discriminate between different habitat types. SVM was also employed to analyse the impact of the multitemporal imagery in the classification accuracy. Results of the analysis showed that the accuracy of grasslands was increased significantly $(p<0.05)$ (in some cases by $20 \%$ ) due to the exploitation of the phenological changes which were represented in the spectral variability. The final habitat map was presented to an expert to assess its quality given the lack of reliable information to quantitatively assess the accuracy of the map. It was concluded that the habitat borders were represented in a satisfactory way (SCHMIDT 2012).

\section{Conclusions}

In this work, an indirect classification method was followed to map habitats in Alpine regions using multi-temporal RapidEye imagery. In particular, the satellite images were initially classified to land-cover classes. For this purpose, the ML, DT and SVM classification algorithms were investigated. Results showed that the SVM algorithm gave the most accurate results. In a subsequent step of the proposed method, the land-cover classes were reclassified to habitat classes using a spatial kernel approach. Findings from 
this work revealed that the inclusion of solar radiation layers in the classification significantly improved the accuracy of the different land-cover classes. Thus, it could be suggested that the use of solar radiation layers can overcome classification difficulties related to radiometric distortions due to topographic effects. Furthermore, the use of multitemporal images improved the overall classification compared to using mono-temporal data as well as the classification accuracy of different grasslands classes by exploiting their temporal changes. Overall, the proposed method not only could provide accurate information on the distribution of habitats in Alpine regions but also could be considered for application on an operational basis given the easy access and relative low cost of the RapidEye imagery. Future work includes investigating whether advanced methods for topographic correction of the RapidEye images could further improve the classification accuracy.

\section{References}

Ellmauer, T. (Ed.) (2005), Lebensraumtypen des Anhangs I der Fauna-Flora-HabitatRichtlinie. Entwicklung von Kriterien, Indikatoren und Schwellenwerten zur Beurteilung des Erhaltungszustandes der Natura 2000-Schutzgüter (Bd. 1-IV, Bd. III). Wien: Im Auftrag der neun österreichischen Bundesländer, des Bundesministerium f. Landund Forstwirtschaft, Umwelt und Wasserwirtschaft und der Umweltbundesamt GmbH.

LaSEN, C. \& Wilhalm, T. (2004), Natura 2000 - Lebensräume in Südtirol. (Autonome Provinz Bozen-Südtirol Abteilung Natur und Landschaft, ed.). Bolzano: Autonome Provinz Bozen-Südtirol.

RapidEye Image Product Frequently Asked Questions (FAQs) (2010), v.1.0, RapidEye AG. SCHMIDT, A. (2012), Conversion of a remote sensed vegetation classification to a habitat map: Comparing spatial kernel and object-based approaches (Master Thesis). Faculty of Geography of the Philipps-Universität Marburg, Marburg/Lahn.

THOOnEN, G. (2012), Contextual classification of hyperspectral remote sensing images Application in vegetation monitoring (PhD thesis). Antwerp, Belgium: University of Antwerp.

Thoonen, G., Spanhove, T., Haest, B., Vanden Borre, J. \& Scheunders, P. (2010), Habitat mapping and quality assessment of heathlands using a modified kernel-based reclassification technique. IGARSS (2707-2710). IEEE International Geoscience \& Remote Sensing Symposium, Honolulu, USA: IEEE.

Thoonen, G., Spanhove, T., VAnden Borre, J. \& Scheunders, P. (2013), Classification of heathland vegetation in a hierarchical contextual framework. International Journal of Remote Sensing, 34 (1), 96-111.

Toutin, T. (2003), Error Tracking in IKONOS Geometric Processing Using a 3D Parametric Model. Photogrammetric Engineering \& Remote Sensing, 69 (1), 43-51.

Varela, R. A. D, Rego, P. R, Iglesias, S. C. \& Sobrino, C. M. (2008), Automatic habitat classification methods based on satellite images: A practical assessment in the NW Iberia coastal mountains. Environmental Monitoring and Assessment, 144, 229-250. 